\title{
SMOKING AMONG STUDENTS IN A RURAL SECONDARY SCHOOL
}

Teh Kok Hoi', Ling Kin Hong ${ }^{2}$

'Medical Student, University of Malaya Medical Centre, ${ }^{2}$ Department of Social and Preventive Medicine, University of Malaya Medical Centre, 50603 Kuala Lumpur, Malaysia

\begin{abstract}
A cross-sectional study on the prevalence of smoking among Form 3, 4 and 5 students of a rural national co-educational school was carried out using a selfadministered questionnaire. By the age of 18 years old, three quarters of boys had tried smoking compared with $12 \%$ of girls. About a third of boys were still smokers while only $0.7 \%$ of girls were still smokers. There was a higher prevalence of smokers among students who stayed with their parents and those who were working part-time. Most smokers knew about the dangerous and addictive effect of cigarette smoking but smoked because of "influence by school peers", "curiosity" and "to increase concentration and decrease tension". (JUMMEC 2000; 2:85-88)
\end{abstract}

KEYWORDS: Cigarette, smoking, prevalence, students.

\section{Introduction}

Although there were many articles published in foreign journals about the prevalence of smoking and its associated factors in different age groups, especially teenagers, few studies were carried out in this country $(1,2,3)$. The objective of this study is to examine the factors that have been found to be associated with smoking in the local context.

Unlike Canada and the United States, the prevalence of smoking among Malaysian females was low $(1,2,3,4,5)$. However, when compared with our neighbour, Singapore, the prevalence of smoking in Malaysia was high (6).

According to Mohamed Ismail (3), $40 \%$ of Form 3 and Form 5 students in Sabak Bernam started to smoke at the age of 14 years old. Thambypillai( $I$ ) had found that the mean age at initiation of cigarette smoking among the Form 4 students of urban schools was 13.3 years old. However, in Singapore, the median age at experimentation was even younger i.e. 12 years old (7).

Studies in Singapore and Canada had linked cigarette smoking among teenagers to a parent (usually the father) who smokes $(4,7)$. Although there is no such study in Malaysia, it was postulated by Hussain Habil (8) that the role of a smoking parent on the development of cigarette smoking among teenagers is very important.

Both foreign $(5,9,10)$ and local researchers (2) have found that most of the students knew about the dan- gerous and/or addictive effect of cigarette smoking. But Kessler (9) had postulated that young people smoked because they did not believe that these dangers applied to them.

Compared to non-smokers, smokers had higher monthly family income and daily pocket money (2).

Nyi Nyi Naing (2) and Mohamed Ismail (3) have found that most students started smoking due to influence by friends. Other reasons included "eagerness to try", to forget problems, to be like an adult and "following father". However, in Singapore, most students smoked "to relax" and "out of sheer curiosity" (7).

Emmanuel (7) has found that most students obtained their first cigarettes from their friends. Nyi Nyi Naing (2) found that most students smoked between I- 5 cigarettes in a day.

Thambypillai ( 1 ) found that $42 \%$ of smokers wished to stop smoking while Mohamed Ismail (3) found that as many as $84 \%$ of smokers wished to stop. Emmanuel (7) also found that most smokers wished to stop.

\section{Materials and Methods}

The study population included all Form 3,4 and 5 students of a rural secondary school with age between 15

Correspondence:

Ling Kin Hong,

Department of Social and Preventive Medicine

University of Malaya Medical Centre

50603 Kuala Lumpur, Malaysia

e-mail: lingkh@medicine.med.um.edu.my 
and 18. The study by Thambypillai (I) showed that the mean age at initiation of smoking was 13.3 years old. However, in Emmanuel's study (7), it was found that it took about 2 years for the experimental smokers to become regular smokers. Hence, the target age group was 15 years old and above.

Data was obtained through a self-administered questionaire written in the Malay language. To obtain maximal responses from the students, the questionnaires were completed under the guidance of trained medical students, in the absence of their teachers. They were also assured that the information gathered would be treated confidentially. As students may deliberately absent themselves to avoid participating in the questionnaire, the students were not informed of the date of the administration of the questionnaire.

\section{Errors and Limitations}

The students may not attempt the questions honestly for fear of being victimized. Some of the students, especially those in poorer academic classes, were not able to understand the questions. Although assisted by our interviewer, some of the answers received were not valid. These answers have been omitted from the analysis.

\section{Definitions}

Definitions pertaining to the smoking status of students are as follows:-

a) Smoker: a person who at the time of the survey, was still smoking

b) Ex-smoker: a person who had stopped smoking

c) Experimental smoker: a person who had tried smoking in the past but did not continue smoking

d) Non-smoker: a person who had never tried smoking before

\section{Results}

Of the 636 targeted students, 564 (88.7\%) responded. The rest ( 47 boys and 25 girls) were absent from school. The number of respondents to different questions in the questionnaire differed slightly due to incompleteness of the answers given by the students.

The respondents comprised of Malay and Indian ethnic groups only, as there were no Chinese students in Form 3,4 and 5 in the school. The Indians made up only $6.9 \%$ of the studied population. Overall, $41.0 \%$ of students had tried smoking in the past. This comprised $34.5 \%$ smokers, $27.9 \%$ ex-smokers and $37.6 \%$ experimental smokers.
More boys than girls smoked (or tried smoking). Among the boys, an overall $74.6 \%$ had tried smoking in the past. This included $29.7 \%$ who were still smoking. On the other hand, among the girls, only $12 \%$ had tried smoking where only $0.7 \%$ were active smokers.

Among those who had tried smoking, the percentages increased with the experience of smoking among the boys $(28.5 \%$ experimental smokers, $31.6 \%$ ex-smokers and $39.9 \%$ smokers). This trend was reversed among the girls $(86.1 \%$ experimental smokers, $8.3 \%$ ex-smokers and $5.6 \%$ smokers).

An unexpected result was that the percentage of smokers among those who stayed with their parents (16.2\%) was two times the percentage of smokers among those who stayed in the school hostel $(8.1 \%)$. The percentages were also lower for other positive smoking categories - $10.4 \%$ of students who stayed in the school hostel compared with $12.7 \%$ of students who stayed with their parents were ex-smokers; $9.6 \%$ compared with $17.3 \%$ were experimental smokers.

Smoking status also changed with working status. As many as $48.8 \%$ of those who were working part-time were smokers, compared with $26.6 \%$ of those who had worked in the past and $5.3 \%$ of those who had never worked before.

Our survey results did not show any significant difference in the prevalence of smoking parents among students with different categories of smoking status.

Knowledge about the danger and the addictive effect of smoking was well established among the student population as evidenced by the fact that as many as $91.1 \%$ of the students knew about these. Only $0.9 \%$ of the students did not know that smoking is dangerous and can lead to addiction.

Survey results showed that overall, majority of students (51.1\%) had smoked without the knowledge of both their parents and school teachers compared with $16.3 \%$ of students who had smoked with the knowledge of both their parents and school teachers. However,among the smokers, the number of students who had managed to smoke secretively (32.4\%) and those whose activities are known to both their parents and teachers (35.3\%) was almost equal. (Table I)

The three most important reasons given by smokers and ex-smokers for their initiation of smoking were "influenced by school peers" ( $65.4 \%$ of smokers and $76.2 \%$ of ex-smokers), curiosity $(60.3 \%$ of smokers and $52.4 \%$ of ex-smokers) and "to reduce tension and increase concentration" ( $39.7 \%$ smokers and $38.1 \%$ exsmokers). However, for the experimental smokers, curiosity $(69.1 \%)$ topped the list followed by "influenced by school peers $(37.0 \%)$ and "to reduce tension and increase concentration" (I2.3\%). (Figure I) 


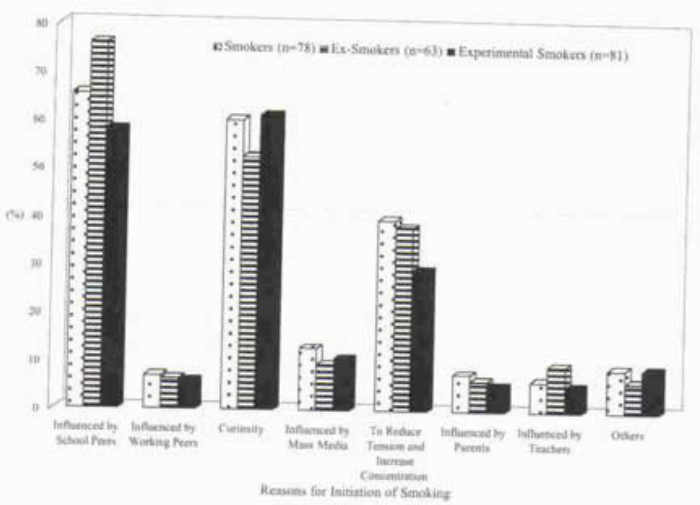

Figure I. Reasons for Initiation of Cigarette Smoking

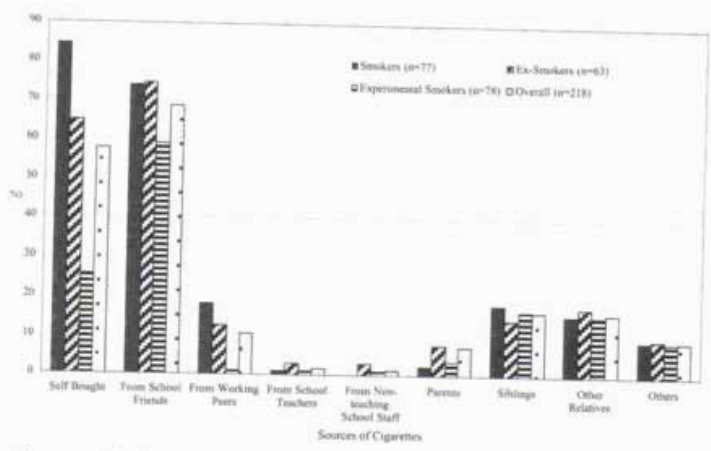

Figure 2. Sources of Cigarettes for Students Who Had Tried Smoking

Table I. Parents' and Teachers' Knowledge about the Smoking Status of Students

\begin{tabular}{llccr}
\hline Parents' and Teachers' Knowledge & \multicolumn{4}{c}{ Smoking Status } \\
\cline { 2 - 5 } & Smokers (\%) & Ex-smokers (\%) & $\begin{array}{l}\text { Experimental } \\
\text { Smokers (\%) }\end{array}$ & Total (\%) \\
\hline Parents and Teachers Know & $24(35.3)$ & $11(17.5)$ & $1(1.3)$ & $36(17.1)$ \\
Parents Know and Teachers Don't Know & $10(14.7)$ & $10(15.9)$ & $16(20.0)$ & $36(17.1)$ \\
Parents Don't Know and Teachers Know & $12(17.6)$ & $10(15.9)$ & $4(5.0)$ & $26(12.3)$ \\
Parents and Teachers Don't Know & $22(32.4)$ & $32(50.8)$ & $59(73.8)$ & $113(53.6)$ \\
\hline Total & $68(30.8)$ & $63(28.5)$ & $80(36.2)$ & $211(100.0)$ \\
\hline
\end{tabular}

More than three quarter of students who had smoked, had easy accessibility to cigarettes. Among the $22.6 \%$ with difficult accessibility, $50.0 \%$ were experimental smokers and $38.0 \%$ were ex-smokers. Most of the students perceived the price of cigarettes as expensive (78.5\%) but not many faced financial difficulties in purchasing them $(50.0 \%)$. This was especially obvious among the smokers ( $57.7 \%$ had no financial difficulties). The percentage of smokers who perceived cigarette as expensive and at the same time faced financial difficulties in purchasing them (34.6\%) was almost the same as the percentage of smokers who perceived cigarette as expensive but did not have any financial difficulties in purchasing them (33.3\%).

Data showed that overall, most of the students had obtained their cigarettes from their school friends $(68.8 \%)$, followed very closely by purchasing them themselves (57.8\%). However, for smokers, $84.4 \%$ managed to buy the cigarettes themselves whereas $74.0 \%$ obtained them from their school friends. (Figure 2)

The mode and median for the amount of cigarettes used per day is 3 . However, the range of cigarettes used per day range from I cigarette per day to 3 I cigarettes per day.

Only $16.0 \%$ of the smokers had thought of trying something stronger than cigarette smoking. Among this, 4 students said they would like to try glue sniffing, 7 students wanted to try ganja while a student would like to try both.
Among the smokers, $61.3 \%$ had the intention to stop smoking and had even tried, but have obviously failed. However, $18.6 \%$ had no intention to quit at all.

\section{Discussion and Conclusion}

The survey had shown that by 18 years old, $74.6 \%$ of boys had tried smoking compared with $12 \%$ of girls. Among the boys who had been initiated to smoking, $39.9 \%$ were current smokers compared to $5.6 \%$ of girls.

The survey also showed that among the boys, the percentage of non-smokers is highest in the 16 years old age group. The authors postulate that this could have been due to the fact that a large number of smokers have stopped schooling after Form 3 (there are only 75 boys in Form 4 compared with 117 boys in Form 3 ). However, further studies will be needed to confirm this hypothesis.

About $8.1 \%$ of students who stayed in the school hostel were smokers compared with $16.2 \%$ of students who stayed with their parents. However, as expected, a higher prevalence of smokers was seen among those who had started working. The authors suggest the need for further studies to look into the reasons for these discrepancies.

Consistent with the findings of Califano (5), $91.1 \%$ of students knew about the danger and addictive effect of cigarette smoking. However, knowledge of someone 
who had contracted an illness or who had died due to cigarette smoking was low among these students. It is probable that although these students knew about the danger and addictive effect of cigarette smoking, they had little sense of their own vulnerability (5).

The three most important reasons for initiation of smoking were "influenced by school peers", curiosity and "to increase concentration and decrease tension". These results are similar to the ones found in Singapore (7) although in Singapore, "to relax" hit the top list and only $13.6 \%$ of smokers "follow friends".

More than three quarter of students who had tried smoking had easy accessibility to cigarettes. However, among those with difficult accessibility, half of them are experimental smokers. Their difficulty in getting cigarettes could have deterred them from continuing the habit. These results should prompt the authority to implement the already-approved national policy not to sell cigarettes to minors. According to Kessler (9), 3 of the ways to reduce cigarette smoking in young adults is to reduce access to cigarettes, to convince danger to self and not to others, and to reduce the number of advertisements.

Again, more than three quarter of students perceived the price of cigarettes as expensive but only half of the students had financial difficulties in purchasing them. Most of the ex-smokers and experimental smokers perceived the price of cigarettes as expensive and faced financial difficulties in purchasing them too. This could have deterred them from continuing to smoke. The act of increasing cigarette taxes every year should decrease the consumption of cigarettes among students $(10)$ as well.

About $70 \%$ of students obtained their cigarettes from their friends while less than $60 \%$ of students purchased these cigarettes themselves. This showed that school friends played a major role in contributing the cigarettes for the students' consumption. As both the students and their friends are minor, implementing the national policy of not selling cigarettes to minor may help in reducing the number of students who smoke.

More than four-fifths of students had intention to quit in the future. This suggests that smoking cessation campaigns should be carried out more vigorously.

\section{Acknowledgements}

The authors wish to thank the students involved in the Community Residency Programme (2000) of the University of Malaya for their assistance in data collection.

\section{References}

I. Thambypillai V, Smoking Among Urban Malaysian School Children. Soc Sci Med 1985; 21 (7): 819-823

2. Naing, Nyi Nyi, Smoking and Discipline Problems among Rural Secondary School Students in Kelantan. Malaysia J of Med Sc 1994; 49 (2): 54 - 58

3. Mohamed Ismail, A Study on the Knowledge, Attitude and Practice on Smoking among Secondary School Children in Sabak Bernam. Bulletin IMR Dec 1993 (Suppl): 24

4. Spurgeon D, Studies Reveal Increase Smoking among Students in Canada. Br Med J, 319: I39| (N)

5. Califano JA, Wrong Way to Stay Slim. N Engl J Med, 1995 , 333 (18): $1214-216$

6. Emmanuel $\mathrm{SC}, \mathrm{Ho} \mathrm{CK}$, Chen AJ, Cigarette Smoking Among School Children in Singapore Part I - Smoking Prevalence. Singapore Med J 1990: 31 (3): 211 - 216

7. Emmanuel SC, $\mathrm{H}_{\circ} \mathrm{CK}$, Chen AJ, Cigarette Smoking among School Children in Singapore Part II - Development of the Smoking Habit. Singapore Med J 1991: 32 (3): 146 150

8. M Hussain Habil, Merokok: Tabiat yang Memerlukan Rawatan. Penerbit Universiti Malaya

9. Kessler DA, Nicotine Addiction in Young People. N Engl ] Med, 333 : 186-189

10. Lawyer EZ, Cole JA, Rabinoff M, Kruszewski SP, Annas G]., Tobacco Litigation. N Engl J Med, 1997, 336: 18321834 